\title{
Spectrum of Cardiovascular Abnormalities in Infants Born to Diabetic Mother in a Tertiary Care Center
}

\author{
A. S. Arul ${ }^{1}$ \\ A. S. Babu Kandha Kumar² \\ K. Kiruthiga ${ }^{2}$
}

M. Kanaga Priya ${ }^{3}$

S. A. Neveythaa ${ }^{4}$

\author{
Address for correspondence Dr. A.S. Arul, MD, DNB, DM (Cardio), \\ FACC, FESC, Department of Cardiology, Tirunelveli Medical College, \\ The Tamilnadu Dr MGR Medical University, A 67, 5th Cross Street, \\ Maharaja Nagar, Tirunelveli,Tamilnadu 627011, India \\ (e-mail: asarul@ymail.com).
}

\begin{abstract}
Keywords

- congenital heart disease

- diabetes

- gestational diabetes

- infants born to diabetic mother

Background Diabetes mellitus is one of the most common medical problems among pregnant women. Now, gestational diabetes mellitus (GDM) is increasing and amounts to $17 \%$ in Asian women but only in $4 \%$ of American and European women. In southern India, the prevalence of GDM is $17 \%$ in urban women, $13.8 \%$ in semiurban, and $9.8 \%$ in rural women.

Aim The aim of the study is to find the cardiovascular abnormalities in infants born to a diabetic mother (IDM) and the association between infant's heart lesion and diabetes mellitus in pregnant mother in a tertiary care center.

Materials and Methods All babies born to both pregestational and gestational diabetic mother were included. Information regarding maternal type of diabetes, treatment regimen, maternal glycemic control status, antenatal ultrasonogram, baby's sex, birth weight, gestational age, and clinical features were collected. Echocardiogram was done for all the babies.

Results Out of the 100 IDM, 28 babies had cardiac disease, 5 babies had cyanotic heart disease, and 23 babies had acyanotic heart disease. Out of 100 diabetic mothers, 66 were on meal plan, 21 were on oral hypoglycemic agent (OHA) metformin, and 13 were on insulin therapy. Among 66 babies whose mother was on the meal plan, 8 had cardiac abnormality. Among the 21 mothers on OHA, 7 babies had cardiac abnormality and all the 13 babies of mothers who were on insulin had cardiac abnormality which was a significant finding among the IDM.

Conclusion Maternal diabetes is a significant risk factor for heart disease in the newborn. Careful evaluation and early diagnosis of heart diseases in this high-risk group is of great value. Both pregestational and gestational diabetic mothers should monitor their blood sugar and maintain it in a normal range at the time of conception and early in pregnancy to reduce the risk of congenital heart disease in IDM.
\end{abstract}

\section{Introduction}

Diabetes mellitus is one of the most common medical problems worldwide. The World Health Organization has predicted that the prevalence of diabetes will increase by 35\% by 2025. ${ }^{1,2}$ Women of Asian origin have more risk of developing diabetes. Now, gestational diabetes mellitus (GDM) is increasing and amounts to $17 \%$ in Asian women but only in
DOI https://doi.org/ 10.1055/s-0039-1697074
(C)2019 Women in Cardiology and Related Sciences
License terms

() (1) $\Theta \circledast$ 
4\% of American and European women., In southern India, the prevalence of GDM was $17 \%$ in urban women, $13.8 \%$ in semiurban, and $9.8 \%$ in rural. ${ }^{5}$

In the infants born to diabetic mother (IDM) the incidence of cardiac anomalies is 3 to $6 \%$ which is five times higher than nondiabetic pregnancy and most of the time it includes complex congenital heart disease. ${ }^{6,7}$ More frequently reported anomalies were conotruncal anomalies such as truncus arteriosus, tricuspid artesia (TA), and transposition of great arteries (TGA). The incidence of TGA in an overt diabetes mother is 17 times more than that of nondiabetic women. ${ }^{8}$ The closure of ductus and decrease in pulmonary pressure were delayed in infants of diabetic mothers compared with a normal neonate. ${ }^{9,10}$

Asymmetrical septal hypertrophy (ASH) seen in IDM is self-limiting with no clinical consequence and is a transient phenomenon which usually regresses within the first few months of life. Septal hypertrophy occurred even in a mother with good glycemic control, without relation to the type of diabetes. ${ }^{11}$ Lisowks et al reported an increased congenital heart disease (CHD) even with slightly elevated HbA1c in their study. Among the factors that may affect the prevalence and severity of cardiac malformation in fetuses of diabetic mothers, poorly controlled diabetic pregnancy has been associated with poorer cardiac function. ${ }^{7,8,17,18}$ As preconceptional maternal glycated hemoglobin is increased cardiac function is reduced. ${ }^{19}$

\section{Materials and Methods}

This cross-sectional study was conducted in the Department of Cardiology, Tirunelveli Medical College Hospital, over a period of one year (April 2017-March 2018) after obtaining ethical committee approval. Infants of diabetic mothers were screened for this study.

Inclusion criteria: All babies born to diabetic mother (both pregestational and gestational diabetic mother) were included. Pregestational-pregnant women who had diabetes before their pregnancy (known diabetic before pregnancy); gestational-pregnant women who had diabetes during their pregnancy (GDM) (nondiabetic before pregnancy).

Exclusion criteria: Babies born with features suggestive of chromosomal abnormality. Babies born to diabetic mothers as still birth and with other comorbidities like hypothyroidism, hypertension, anemia complicating pregnancy, and seizure disorder on antiepileptic drugs were excluded.

All babies satisfying the inclusion criteria were enrolled for study after obtaining informed consent. At first, a data sheet was completed for each newborn with the following information: maternal type of diabetes, treatment regimen, maternal glycemic control status, antenatal ultrasonogram, baby's sex, birth weight, gestational age, and clinical features. Parameters used for glycemic control assessment was Hba1C. Values less than 6.5 were considered as good glycemic control and values more than 6.5 were considered as poor glycemic control.

All infants underwent a thorough physical examination with special attention to the cardiovascular system and the following investigations were done: oxygen saturation-by pulse oximetry, electrocardiogram, chest X-ray, and echocardiogram (ECG). Data were collected and recorded in the pro forma during the whole study period and entered in Microsoft Excel sheet and analyzed to identify the relation between maternal diabetes and cardiovascular abnormality among the IDM. The software used in this study for statistical analysis was SPSS software version 21.0 (IBM). Tests used for comparing mean were $t$-test and ANOVA (Analysis Of Variance). For comparing the relation between groups, Chi-square and Kruskal-Wallis tests were used.

\section{Results}

In the present study 100 diabetic mothers were included and their babies were screened for cardiac abnormalities. Among them, 17 mothers had pregestational diabetes and 83 mothers had gestational diabetes. Out of the 17 mothers with pregestational diabetes, 16 babies had cardiac abnormalities and 12 babies of the 83 mothers with gestational diabetes had echocardiography studies suggesting cardiac abnormalities. The ECHO abnormality was significantly more in the pregestational diabetes group $(\mathrm{P}$ value $=0.001)(-$ Table $\mathbf{1})$.

Out of the 100 mothers, 93 had good glycemic control and 7 had poor glycemic control. In this study 21 babies born to mothers with good glycemic control and 7 babies born to mothers with poor glycemic control had cardiac abnormality (-Table 2).

There was significant influence of maternal diabetes treatment regimen in the outcome of cardiac abnormality among IDM. Out of 100 diabetic mothers, 66 were on meal plan, 21 were on oral hypoglycemic agent (OHA) metformin, and 13 were on insulin therapy. Among 66 babies whose mothers were on the meal plan, 8 had cardiac abnormality. Of the 21 mothers on OHA, 7 babies had cardiac abnormality and 13 insulin taking mothers, 13 babies had cardiac abnormality (-Table 3).

Out of the 100 IDM, 28 babies had cardiac disease, 5 babies had cyanotic heart disease, and 23 babies had acyanotic heart disease. Out of the 66 mothers on meal plan, 8

Table 1 Type of diabetes and cardiac abnormalities

\begin{tabular}{|l|l|l|}
\hline \multirow{2}{*}{ Diabetes } & \multicolumn{2}{|l|}{ Cardiac abnormality } \\
\cline { 2 - 3 } & Present & Absent \\
\hline Pregestational & 16 & 1 \\
\hline Gestational & 12 & 71 \\
\hline Total & 28 & 72 \\
\hline Chi-square test $P$ value: 0.001 & \\
\hline
\end{tabular}

Table 2 Maternal glycemic control and cardiac abnormality

\begin{tabular}{|l|l|l|l|}
\hline Glycemic status & $\begin{array}{l}\text { No. of } \\
\text { mothers }\end{array}$ & \multicolumn{2}{|l|}{ Cardiac abnormality } \\
\cline { 3 - 4 } & & Present & Absent \\
\hline Good & 93 & 21 & 72 \\
\hline Poor & 7 & 7 & - \\
\hline Total & 100 & 28 & 72 \\
\hline
\end{tabular}


Table 3 Treatment regimen and cardiac abnormalities

\begin{tabular}{|l|l|l|l|}
\hline Treatment regimen & Mothers $(\boldsymbol{n}=\mathbf{1 0 0})$ & Babies with cardiac abnormality & Babies normal cardiac status \\
\hline Meal plan & $66 \%$ & $8(12 \%)$ & 58 \\
\hline $\begin{array}{l}\text { Oral hypoglycemic } \\
\text { agent }\end{array}$ & $21 \%$ & $7(33 \%)$ & 14 \\
\hline Insulin & $13 \%$ & $13(100 \%)$ & 00 \\
\hline Total & 100 & $28(28 \%)$ & 72 \\
\hline \multicolumn{2}{|l}{ Kruskal-Wallis test $(\boldsymbol{p}$-Value $\mathbf{0 . 0 0 1 )}$ : significant } \\
\hline
\end{tabular}

babies had cardiac abnormality and all the 8 babies had acyanotic heart disease-atrial septal defect (ASD) in 4, patent foramen ovale (PFO) in 3, patent ductus arteriosus (PDA) in 1. Among the 21 mothers on OHA metformin, 7 babies had cardiac abnormality and all the 7 babies had acyanotic heart disease-ASD in 1, ventricular septal defect (VSD) in 2, PFO in 1, PDA in 1, asymmetrical septal hypertrophy (ASH) in 2. But among the 13 mothers on insulin there were babies with acyanotic as well as cyanotic heart diseases, 5 babies had cyanotic congenital heart disease (CCHD-transposition of great arteries (TGA) in 2, hypoplastic left heart syndrome (HLHS) in 1, TA (1), truncus arteriosus (1) and 8 babies had acyanotic congenital heart disease (ACHD)-ASD in 1,VSD in 1,PDA in $1, \mathrm{ASH}$ in 4 , and PFO in 1 (-Table 4).

Table 4 Treatment regimen and spectrum of cardiac abnormalities

\begin{tabular}{|l|l|l|l|}
\hline Cardiac abnormality & $\begin{array}{l}\text { Meal plan } \\
\text { ACHD }\end{array}$ & $\begin{array}{l}\text { OHA } \\
n=21\end{array}$ & $\begin{array}{l}\text { Insulin } \\
n=13\end{array}$ \\
\hline ASD & 4 & 1 & 0 \\
\hline VSD & 0 & 2 & 2 \\
\hline PDA & 1 & 1 & 1 \\
\hline ASH & 0 & 2 & 5 \\
\hline PFO & 3 & 1 & 0 \\
\hline CCHD & Meal plan & OHA & Insulin \\
\hline TGA & 0 & 0 & 2 \\
\hline Truncus arteriosus & 0 & 0 & 1 \\
\hline TA & 0 & 0 & 1 \\
\hline HLHS & 0 & 0 & 1 \\
\hline Total & 8 & 7 & 13 \\
\hline
\end{tabular}

Abbreviations: OHA, oral hypoglycemic agent; ASD, atrial septal defect; ASH, asymmetrical septal hypertrophy; HLHS, hypoplastic left heart syndrome; PDA, patent ductus arteriosus; PFO, patent foramen ovale; TA, tricuspid artesia; TGA, transposition of great arteries; VSD, ventricular septal defect.

Table 5 Presentation of disease and extent of ECHO abnormality

\begin{tabular}{|l|l|l|l|}
\hline Presentation & $\begin{array}{l}\text { Total no. } \\
\text { of babies } \\
\text { examined } \\
\text { (n) }\end{array}$ & $\begin{array}{l}\text { ECHO abnormality } \\
(\mathbf{n})(\%)\end{array}$ \\
\cline { 2 - 4 } & Present & Absent \\
\hline Symptomatic & $\mathbf{1 5}$ & $13(86.6)$ & $2(13.33)$ \\
\hline Asymptomatic & $\mathbf{8 5}$ & $15(17.64)$ & $70(82.35)$ \\
\hline
\end{tabular}

Among the 100 IDM, 4 were small for gestational age (SGA), 80 were appropriate for gestational age (AGA), 16 were large for gestational age (LGA). ECHO abnormality was present in all groups. Out of the 100 babies admitted in the Neonatal Intensive Care Unit (NICU), 15 were with symptoms and 85 were asymptomatic. Among 15 symptomatic babies, 13 had cardiac abnormality and among the 85 asymptomatic babies, 15 had cardiac abnormality (-Table 5 ).

Out of the 100 newborns taken in the study, 14 newborns had murmur and 86 newborns had no murmur. Out of the 14 newborn babies with murmur, 11 had ECHO abnormality. Out of the 86 newborn babies without a murmur, 17 had ECHO abnormality. All newborns with abnormal $\mathrm{SpO}_{2}$ had cardiac abnormality, signifying the importance of $\mathrm{SpO}_{2}$ monitoring (-Table 6).

\section{Discussion}

GDM complicates 1 to $3 \%$ of all pregnancies. Different studies showed that congenital anomalies occur three to five times more commonly in the IDM than in the general population. ${ }^{12}$

In the present study, 100 IDM were subjected to ECG; of this, 28 (28\%) babies had cardiac abnormality. Among them 5 babies had CCHD and 23 babies had ACHD. A similar study done on cardiovascular malformations in IDM by Meyer et al showed a lower incidence of 3.2 to 6.9 and a study by Tabib et al showed an incidence of $8.8 \% .^{13,14}$

Of the 100 IDM babies studied $17 \%$ of the mothers were found to have pregestational diabetes and $83 \%$ were found to have gestational diabetes. In this study $94 \%$ of babies born to mothers with pregestational diabetes had cardiac abnormality when compared with $14 \%$ babies born to mothers with gestational diabetes, which was a significant finding. Out of the 28 babies who showed cardiac abnormality, 16 babies (57\%) were born to mothers with pregestational diabetes and 12 babies (43\%) were born to mothers with gestational

Table 6 Murmur and ECHO abnormality in IDM

\begin{tabular}{|l|l|l|l|}
\hline Murmur & $\begin{array}{l}\text { Total no. of } \\
\text { babies } \\
\text { examined } \\
(n=100)\end{array}$ & \begin{tabular}{l} 
ECHO abnormality \\
\cline { 2 - 4 }$(n=28)$
\end{tabular} & $\begin{array}{l}\text { Absent } \\
(n=72)\end{array}$ \\
\hline $\begin{array}{l}\text { Babies with } \\
\text { murmur }\end{array}$ & 14 & 11 & 3 \\
\hline $\begin{array}{l}\text { Babies without } \\
\text { murmur }\end{array}$ & 86 & 17 & 69 \\
\hline
\end{tabular}


diabetes. Of the 16 babies born to mothers with pregestational diabetes, 11 babies (68.7\%) had ACHD and 5 babies (31.3\%) had CCHD. All the 12 babies born to mothers with gestational diabetes had acyanotic disease.

Mothers with pregestational diabetes who closely monitor and keep their blood sugar in the normal range at the time of conception and early in pregnancy have a much lower risk of having a baby with CHD. Currently the American Heart Association recommends that all pregestational diabetic women undergo a fetal ECG between 18 and 22 weeks of gestation to thoroughly assess the developing baby for the possibility of CHD.

In this study, among the 100 IDM babies, 93\% of mothers had well-controlled glycemic status and $7 \%$ had poorly controlled glycemic status. ECHO abnormality was found to be more significant in babies born to mothers with poorly controlled diabetes with a preponderance of cyanotic heart disease. It showed that the mother's glycemic status had a significant influence on cardiovascular anomalies, which is compatible with the studies done by Khan et al and Mekwana et al. ${ }^{15,16}$ Babies of mothers with poorly controlled glycemic status had poorer cardiac function. ${ }^{17,18}$

Increase in blood sugar levels in the mother leads to high blood sugar in the developing fetus, thus creating an abnormal biochemical environment which will have negative impact on genes responsible for normal development. The types of congenital heart defects associated with maternal diabetes are known to form very early in pregnancy.

In this study with 100 IDM babies, 14 babies presented with a murmur, 5 babies with low $\mathrm{SpO}_{2}$, and 3 babies with external congenital anomalies like polydactyl and cleft palate. Of the 14 babies with murmur, 11 babies (78\%) had ECHO abnormality and all babies with low $\mathrm{SpO}_{2}$ and external congenital anomalies had ECHO abnormality. IDM babies whose X-rays showed cardiomegaly (9\%) had ECHO abnormality more of septal hypertrophy. Abnormal ECG was found in 8 babies out of the 100 examined and all had ECHO abnormality more of septal hypertrophy, ASD, and TGA.

In acyanotic heart diseases, ASH was detected more than other cardiac abnormalities. On studying the relation between the type of heart lesion and maternal diabetes, septal hypertrophy was more in pregestational diabetic mother ( 7 out of 17) followed by ASD (3), VSD (2), and PDA (1). This was in concordance with the previous studies done by Tabib et al and Zielinsky et al. ${ }^{14,19}$

Babies born to pregestational diabetic mothers showed more cyanotic heart disease, TGA (2), TA (1), truncus arteriosus (1), and HLHS (1), and babies born to GDM mothers had more acyanotic heart disease. On studying the relationship between maternal diabetes and treatment plan, babies whose mothers were on insulin had several ECHO abnormality. Of which, 5 babies had cyanotic heart disease-TGA (2), HLHS (1), tricuspid atresia (1), and truncus arteriosus (1). Babies whose mothers were on meal plan also had cardiac abnormality but of acyanotic heart disease-ASD (4), PFO (3), and PDA (1). Mothers with OHA treatment had ECHO abnormality of ASD (1), VSD (2), PFO (1), PDA (1), and ASH (2).
Based on diabetic control, babies born to mothers with poor glycemic control, had significant ECHO abnormality with more incidence of cyanotic heart disease-TGA (2), TA (1), HLHS (1), truncus arteriosus (1), and acyanotic heart disease-ASH (1) and ASD (1). Most of the babies born to well-controlled mothers had more of acyanotic heart disease, with increased ASH (6), PFO (4), VSD (4), PDA (3), and ASD (4).

\section{Conclusion}

CHD is more common among IDM. Among CHD, acyanotic heart disease was more common than cyanotic heart disease. Among acyanotic heart disease ASH was more common than ASD, VSD, PDA, and PFO. Among the cyanotic heart disease, transposition of great arteries, HLHS, tricuspid atresia, and truncus arteriosus were more common.

A better understanding of the clinical impact of the maternal hyperglycemic status on offspring's health early in life is needed to form strategies for the prevention of cardiovascular disease in IDM. A long-term follow-up of children is mandatory for further assessment of their cardiovascular health.

\section{Limitations of the study}

In our study, HbA1c level was measured only once during the pregnancy period. So its effect on organogenesis specifically could not be interpreted. Fetal echocardiogram was not done in all babies.

\section{Conflict of Interest}

None.

\section{References}

1 Ang C, Howe D, Lumsden M. In: James DK, Steer PJ, Weiner CP, and Gonik B, eds. High Risk Pregnancy Management Options. 3rd ed. Philadelpia, PA: Saunders; 2005 986- 1004

2 Thomas N, Chinta AJ, Sridhar S, Kumar M, Kuruvilla KA, Jana AK. Perinatal outcome of infants born to diabetic mothers in a developing country-comparison of insulin and oral hypoglycemic agents. Indian Pediatr 2013;50(3):289-293

3 FerraraA.Increasing prevalence of gestational diabetes mellitus: a public health perspective. Diabetes Care 2007;30 (Suppl 2): S141-S146

4 Seshiah V, Balaji V, Balaji MS, et al. Prevalence of gestational mellitus in south india. A community basedstudy. J Assoc Physicians India 2008;56:329-333

5 Ramachandran A, Snehalatha C, Shymala P. Vijay V, Vishwanathan M. Prevalence of diabetes in South India. Diabetes Res Clin Pract 1994;25:71-74

6 Ullmo S, Vial Y, Di Bernardo S, Roth Kleiner M, Mivaelaz Y, Sekarski N, et al. Ventricular hypertrophy in the offspring of diabetic mother: a retrospective study. Eur Heart J 2007;28: 1319-1325

7 Lisowski LA, Verheij En PM, Copel JA, et al. Congenital heart disease in pregnancies complicated by diabetes. An international collaboration, literature review, and meta-analysis. Herz 2010;35(1):19-26

8 Wren C, Birrell G, Hawthorne G. Cardiovascular malformations in infants of diabetic mothers. Heart; 2003 Oct; 89(10):1217-1220

9 Vela-Hurta M, Aguilera L A, Alarcon Santos S, Amador N, Aldana C. Cardiopulmonary adaptation in large for gestational 
age infants of diabetic mother and non diabetic mother. Acta Paediatr 2007;96(9):1303-1307

10 Seppänen MP, Ojanperä OS, Kääpä PO, Kero PO. Delayed postnatal adaptation of pulmonary hemodynamics in infants of diabetic mothers. J Pediatr 1997;131(4):545-548

11 Oberhoffer R, Högel J, Stoz F, Kohne E, Lang D. Cardiac and extracardiac complications in infants of diabetic mothers and their relation to parameters of carbohydrate metabolism. Eur J Pediatr 1997;156(4):262-265

12 Ferdousi AS, Sarker FR, Jahan N, Fatema N. Pattern of congenital heart disease in infants of diabetic mother. Bangladesh J Child Health 2014;38(2):74-78

13 Meyer-Wittkopf M, Simpson JM, Sharland GK. Incidence of congenital heart defects in fetuses of diabetic mothers: a retrospective study of 326 cases. Ultrasound Obstet Gynecol 1996;8(1):8-10

14 Tabib A, Shirzad N, Sheikhbahaei S, et al. Cardiac malformations in fetuses of gestational and pre gestational diabetic mothers. Iran J Pediatr 2013;23(6):664-668
15 Kahn SE, Hull RL, Utzschneider KM. Mechanisms linking obesity to insulin resistance and type 2 diabetes. Nature 2006;444(7121):840-846

16 Makwana M, Dabi JC, Soni JP, Bhati RL, Mourya HK, Garg Y. The clinical evaluation of the infants of diabetic mothers (IDMS) born in a tertiary care hospital. Int J Contemp Pediatr 2017;4:1228-1231

17 Bruyere HJ, Jr. Kargas SA, Levy JM. The causes and underlying mechanism congenital cardiac malformations. A critical review. Am J Med Genet Suppl 1987;3:411-431

18 Cedegren MI, Selbing AJ, Kallen BA. Risk factor for cardiac malformations astudy based on prospectively collected data. Scand J Work Environ Health 2002;28(1):12-17

19 Zielinsky P, Piccoli A, Jr. Diseases of the myocardium, endocardium and pericardium during fetal life. In: Yagel S, Silverman $\mathrm{N}$, Cohen SM, editors. Fetal Cardiology: Embryology, Genetics, Physiology, Echocardio- graphic evaluation, Diagnosis and Perinatal Management of Cardiac Disease. 2nd ed. New York. Informa Healthcare; 2009. p. 366 